\title{
Rhodnius prolixus interaction with Trypanosoma rangeli: modulation of the immune system and microbiota population
}

Cecilia S Vieira ${ }^{1}$, Débora P Mattos ${ }^{1}$, Peter J Waniek ${ }^{1}$, Jayme M Santangelo ${ }^{3}$, Marcela B Figueiredo ${ }^{1}$, Marcia Gumiel ${ }^{1}$, Fabio F da Mota ${ }^{1,2}$, Daniele P Castro ${ }^{1,2}$, Eloi S Garcia ${ }^{1,2}$ and Patrícia Azambuja ${ }^{1,2^{*}}$

\begin{abstract}
Background: Trypanosoma rangeli is a protozoan that infects a variety of mammalian hosts, including humans. Its main insect vector is Rhodnius prolixus and is found in several Latin American countries. The R. prolixus vector competence depends on the T. rangeli strain and the molecular interactions, as well as the insect's immune responses in the gut and haemocoel. This work focuses on the modulation of the humoral immune responses of the midgut of $R$. prolixus infected with $T$. rangeli Macias strain, considering the influence of the parasite on the intestinal microbiota.

Methods: The population density of T. rangeli Macias strain was analysed in different $R$. prolixus midgut compartments in long and short-term experiments. Cultivable and non-cultivable midgut bacteria were investigated by colony forming unit (CFU) assays and by 454 pyrosequencing of the $16 \mathrm{~S}$ rRNA gene, respectively. The modulation of $R$. prolixus immune responses was studied by analysis of the antimicrobial activity in vitro against different bacteria using turbidimetric tests, the abundance of mRNAs encoding antimicrobial peptides (AMPs) defensin (DefA, DefB, DefC), prolixicin (Prol) and lysozymes (LysA, LysB) by RT-PCR and analysis of the phenoloxidase (PO) activity.

Results: Our results showed that T. rangeli successfully colonized $R$. prolixus midgut altering the microbiota population and the immune responses as follows: 1 - reduced cultivable midgut bacteria; 2 - decreased the number of sequences of the Enterococcaceae but increased those of the Burkholderiaceae family; the families Nocardiaceae, Enterobacteriaceae and Mycobacteriaceae encountered in control and infected insects remained the same; 3 - enhanced midgut antibacterial activities against Serratia marcescens and Staphylococcus aureus; 4 - downregulated $L y s B$ and Prol mRNA levels; altered DefB, DefC and LysA depending on the infection (short and longterm); 5 - decreased PO activity.
\end{abstract}

Conclusion: Our findings suggest that $T$. rangeli Macias strain modulates $R$. prolixus immune system and modifies the natural microbiota composition.

Keywords: Rhodnius prolixus, Trypanosoma rangeli, Immune system, Prophenoloxidase, Antimicrobial peptide

\footnotetext{
* Correspondence: azambuja.p@gmail.com

${ }^{1}$ Laboratório de Bioquímica e Fisiologia de Insetos, Instituto Oswaldo Cruz,

Fundação Oswaldo Cruz (IOC/FIOCRUZ), Rio de Janeiro, RJ, Brazil

${ }^{2}$ Departamento de Entomologia Molecular, Instituto Nacional de

Entomologia Molecular (INCT-EM), Rio de Janeiro, RJ, Brazil

Full list of author information is available at the end of the article
} 


\section{Background}

The haemoflagellate, Trypanosoma rangeli, is a protozoan parasite that infects a large number of mammals, including humans, and it is vectored by triatomine insects, especially the genus Rhodnius [1-4]. The interaction with triatomine hosts, such as Rhodnius prolixus, begins with the ingestion of an infective blood meal containing $T$. rangeli. After ingestion, the parasites transform into epimastigotes, then multiplies in the insect gut, and invades the haemolymph. To perpetuate the infection they transform into the metacyclic forms in the salivary glands $[1,2,5]$. The life cycle of $T$. rangeli is completed with the transmission of the parasite to vertebrate hosts by the vector through its salivary gland secretions during a blood meal [6,7].

The establishment of $T$. rangeli infections in both the digestive tract and haemocoel is regulated by physiological processes of the triatomine vector [8]. The parasites survive despite the activation of innate immune reactions and complete their life cycle in the insect host [9-11]. Once inside the midgut, the parasites must interact with blood digestion products as well as midgut components including bacterial microbiota [12,13], haemolytic factors [14,15], lectins [16], the prophenoloxidase (PPO) system [17], antimicrobial peptides (AMPs) [18,19] and reactive nitrogen and oxygen species [20].

Some of these factors act as biological barriers to the infection of $T$. rangeli in the vector gut. However, the $T$. rangeli infection may lead to immunedepression of the insect host by the inhibition of phagocytosis, haemocyte microaggregation, PPO activation and eicosanoids synthesis $[11,21,22]$. These physiological alterations allow the parasites to overcome the immune response, reach the salivary glands and complete their life cycle.

Knowledge of the modulation of the triatomine immune system by the numerous strains of $T$. rangeli is still poorly understood. Thus, the aim of the present study was to investigate the effects of $T$. rangeli Macias strain infection on the midgut immune responses, parasite development and bacteria population of $5^{\text {th }}$ instar nymphs of $R$. prolixus orally infected with parasites. In addition to the evaluation of the effects of $T$. rangeli in short-term infections, long-term infections were analysed in the $5^{\text {th }}$ instar nymphs previously infected in the $4^{\text {th }}$ instar stage. The present results suggest that the parasites modulate the $R$. prolixus immune responses, affecting the intestinal microbiota by inhibiting activation of prophenoloxidase, altering the abundance of antimicrobial peptide transcripts and enhancing antimicrobial activities against Serratia marcescens. These results provide further elucidation of the $T$. rangeli- $R$. prolixus interaction.

\section{Methods}

\section{Ethics Statement}

Defibrinated rabbit blood provided by the Animals Creation Center Laboratory (Cecal/Fiocruz) was provided to the insects through an artificial apparatus respecting the guidelines of the Ethics Committee on Animal Use (Ceua/Fiocruz). CEUA follows the Ethical Principles in Animal Experimentation composed by Fiocruz researchers and external consultants. The protocol number L-0061/08 was established by CONCEA/MCT [23].

\section{Maintenance of Trypanosoma rangeli epimastigotes}

T. rangeli Macias strain, first isolated from a human in Venezuela [24,25] and later characterized as genotype KP1+ [26], was kindly supplied by Dr. Suzete Gomes, Universidade Federal Fluminense (Rio de Janeiro, Brazil). The parasites were maintained at $28^{\circ} \mathrm{C}$ in brain heart infusion (BHI) media (Sigma-Aldrich, São Paulo, Brazil) supplemented with $20 \%$ heat-inactivated bovine foetal serum [27] and subcultured twice a week. This procedure keeps the parasite in the log phase growth resulting predominantly in short epimastigotes (99\%). The number of parasites was quantified in a Neubauer chamber.

\section{Bacteria preparation}

Staphylococcus aureus 9518, and Escherichia coli K12 4401 were purchased from the National Collection of Industrial and Marine Bacteria (NCIMB), Aberdeen, UK. $S$. marcescens $\mathrm{RPH}$ was previously isolated from $R$. prolixus [12] and maintained at Laboratório de Bioquímica e Fisiologia de Insetos. The bacteria were maintained at $-70^{\circ} \mathrm{C}$ in tryptone agar and $10 \%$ glycerol. For all experimental procedures, bacteria were grown as previously described [28]. Briefly, bacteria were grown overnight in tryptone soy broth (TSB) at $30^{\circ} \mathrm{C}$ and then cultured in fresh TSB for a further $4 \mathrm{~h}$ under the same conditions. The bacteria were then washed in phosphate buffered saline (PBS, $0.01 \mathrm{M}$ phosphate buffer, $2.7 \mathrm{mM}$ potassium chloride and $0.137 \mathrm{M}$ sodium chloride, $\mathrm{pH}$ 7.4) and resuspended in TSB to a final concentration of $1 \times 10^{4}$ cells $/ \mathrm{ml}$.

\section{Insect oral infection: long and short-term infections}

Insects were kept at $27^{\circ} \mathrm{C}$ and fed artificially with defibrinated rabbit blood [27]. All insects were fed on blood, after heat-inactivation of the plasma. The blood was centrifuged at $1,890 \mathrm{x} \mathrm{g}$ for $10 \mathrm{~min}$ at $4^{\circ} \mathrm{C}$ and the supernatant (plasma) was incubated for $30 \mathrm{~min}$ at $55^{\circ} \mathrm{C}$. The plasma was added back to the erythrocytes and then received $T$. rangeli epimastigotes obtained from culture. The same procedure of plasma inactivation was undertaken for control insects.

For long-term experiments, inactivated blood containing $1 \times 10^{6}$ epimastigotes $/ \mathrm{mL}$ (infected group) or blood 
without parasites (control uninfected group) was given to $4^{\text {th }}$ instar nymphs. After moulting to $5^{\text {th }}$ instars, both insect groups received a non-infective blood meal which occurred 38 days after feeding (DAF) of the 4th instar nymphs. For short-term experiments, $5^{\text {th }}$ instar nymphs were fed on blood containing $1 \times 10^{6}$ epimastigotes $/ \mathrm{mL}$ or with parasite-free blood. Only fully engorged insects were used for all experiments.

\section{Quantification of parasites in the digestive tract}

Fifth instar nymphs obtained from long or short-term experiments were dissected. The anterior midgut (stomach) was collected and homogenized in $1.0 \mathrm{~mL}$ PBS and the posterior midgut (intestine) plus rectum was placed in $50 \mu \mathrm{L}$ in PBS. Samples were macerated and the number of parasites was determined by counting in a Neubauer haemocytometer and expressed as parasites $/ \mathrm{mL}$. Parasites were quantified in three experiments with five insects each $(\mathrm{n}=15)$.

\section{Analysis of intestinal microbiota Colony forming unit (CFU)}

Anterior midgut contents obtained from $5^{\text {th }}$ instar nymphs infected or uninfected with parasites (short and long-term infections) were analysed for microbiota bacterial population using CFU at 12 DAF. The midgut contents were serially tenfold diluted with PBS and $20 \mu \mathrm{L}$ was spread on a Petri dish in BHI agar (Sigma-Aldrich) culture medium. The plates were incubated at $30^{\circ} \mathrm{C}$ for $24 \mathrm{~h}$ and the CFU counted. As a control, PBS was also plated to check the sterility of all experiments.

\section{Metagenomic DNA extraction}

Seven days after insect feeding (long-term infection), metagenomic DNA was extracted from the anterior midgut contents of four $T$. rangeli infected insects and four uninfected $R$. prolixus $5^{\text {th }}$ instar nymphs by an unbiased and efficient mechanical lysis method [29]. The extraction was carried out using the commercial Fast-DNA ${ }^{\mathrm{m}}$ Spin Kit for Soil (Qbiogene, MP Biomedicals, USA) following the manufacturer's instructions. DNA extracts were visualized on $1 \%$ agarose gels to assess their integrity and purity.

\section{Amplification and 454 sequencing of targeted 16S rRNA gene variable region}

For quantitative analysis of bacterial microbiota in long-term infected insects, ribosomal genes from metagenomic DNA samples were amplified using bar-coded primers for the $16 \mathrm{~S}$ variable region V3-V1, cleaned up, quantified and normalized according to the HMP 3730 $16 \mathrm{~S}$ protocol version 4.2 [30], which is available on the HMP Data Analysis and Coordination Center website [31]. The PCR products obtained were then submitted to FLX-Titanium pyrosequencing in a GS Junior System (Roche).

The raw sequences were analysed using the RDP Pipeline with default parameters. Sequences with a score below the quality threshold were discarded and the sequence portions devoted to 454 sequencing were trimmed out. Sequences with more than 400 bases were then aligned using the INFERNAL aligner [32] and chimeric sequences detected (and removed) with UCHIME [33]. Taxonomical classification was assigned using the RDP classifier $[34,35]$ with a minimum confidence level for record assignment set to 0.80 .

\section{Turbidimetric antibacterial assay}

In long and short-term experiments, the antibacterial activities of the anterior midgut contents from $5^{\text {th }}$ instar nymphs infected or not with $T$. rangeli were tested at 7 DAF, according to previous studies which have shown that the maximal antibacterial activity is reached at this time $[17,36]$. Fifth instar nymphs of $R$. prolixus were dissected to collect the anterior midgut. The midgut walls were removed and the midgut contents pooled (3 insects) in $200 \mu \mathrm{l}$ ultrapure water, homogenized, centrifuged at $10,000 \times \mathrm{g}$ for $10 \mathrm{~min}$ at $4^{\circ} \mathrm{C}$ and filtered by a sterile PVDF membrane (Millipore) and stored at $-20^{\circ} \mathrm{C}$ until use. Before assaying, the midgut content samples were diluted ten times in sterile water. Subsequently, $10 \mu \mathrm{l}$ of E. coli, S. aureus or S. marcescens bacterial suspensions $\left(10^{4}\right.$ cells $\left./ \mathrm{mL}\right)$ were added to each well of a sterile flat bottom 96-well microtiter plate (Nunc, Fisher Scientific, Leicestershire, UK) with $45 \mu \mathrm{l}$ of diluted midgut samples and $5 \mu \mathrm{l}$ of peptone $10 \%$ and incubated at $37^{\circ} \mathrm{C}$ for $19 \mathrm{~h}$. The optical densities were measured at $550 \mathrm{~nm}\left(\mathrm{OD}_{550}\right)$ at hourly intervals using a Spectra Max 190 Plate Reader (Molecular Devices, Sunnyvale, USA). Control wells, run without anterior midgut samples, contained $10 \mu \mathrm{l}$ of bacteria in a final concentration of $1 \%$ peptone in ultrapure water. Ampicillin $(80 \mu \mathrm{g} / \mathrm{ml})$ was included in each experiment as an antibiotic control. To exclude the opacity of the midgut samples all data points were blanked against time zero. The antibacterial activity was calculated by subtracting the bacterial growth readings (control wells) from the respective values of anterior midgut samples incubated with bacteria.

\section{Transcript abundance of antimicrobial peptides}

Transcript abundance of genes encoding antibacterial peptides in short and long-term experiments with $T$. rangeli infected and uninfected $5^{\text {th }}$ instar nymphs was analysed by reverse transcription PCR (RT-PCR) as described previously [36]. In brief, the anterior and posterior midgut walls of a pool of ten insects were dissected from $5^{\text {th }}$ instar nymphs 1 and 7 DAF. Total 
RNA was extracted using the NucleoSpin ${ }^{\circ}$ RNA II Kit (Macherey-Nagel, Düren, Germany), following the manufacturer's instructions. RNA concentration was measured on a NanoDrop 2000 (Thermo Scientific, Waltham, USA). For cDNA synthesis, 1.25 or $2.5 \mu \mathrm{g}$ of total RNA was performed using a First-Strand cDNA Synthesis Kit (GE Healthcare, Buckinghamshire, UK). Oligonucleotide primers for amplification of defensin A, B and C, lysozyme A and B, prolixicin $[19,37,38]$ and $B$-actin (endogenous control) were used. PCRs were carried out in triplicate on a Veriti 96 thermocycler (Applied Biosystems, Carlsbad, USA) using an IllustraTaq DNA-Polymerase (GE Healthcare). In negative PCR controls, ultrapure water was added instead of cDNA. PCR products were electrophoretically separated on a $2 \%$ agarose gel and stained with ethidium bromide. Gels were documented using an E-Gel ${ }^{\circ}$ Imager (Life Technologies, Carlsbad, USA) and band intensity quantified using the ImageJ program (v. $1.47 q)$.

\section{Determination of phenoloxidase activity}

Phenoloxidase (PO) activities were analysed in samples of the anterior midgut contents freshly prepared from $5^{\text {th }}$ instar nymphs obtained from long and short-term experiments. Each midgut content was diluted in $200 \mu \mathrm{L}$ of ultrapure water, centrifuged at 10,000 $\mathrm{x}$ g for $10 \mathrm{~min}$ and the supernatant ten times diluted. For PO analysis, five insects were used from each group. The experiments were carried out in triplicate and at 7 and 12 DAF.

PO activity was determined by measuring the dopachrome formation from DOPA using midgut samples, as described previously [39]. For assaying, $25 \mu \mathrm{L}$ of a midgut preparation was mixed with $10 \mu \mathrm{L}$ of cacodylate$\mathrm{CaCl}_{2}$ buffer (10 mM sodium cacodylate, $10 \mathrm{mM} \mathrm{CaCl}_{2}$, $\mathrm{pH}$ 7.4). After the addition of $25 \mu \mathrm{L}$ of a saturated solution of DOPA $(4 \mathrm{mg} / \mathrm{mL})$, the absorbance at $490 \mathrm{~nm}$ was measured continually in a Spectra Max 190 Microplate Reader at $37^{\circ} \mathrm{C}$ for $120 \mathrm{~min}$. The enzyme unit was expressed as absorbance $/ \mathrm{min} \times 100$.

\section{Statistical analysis}

Depending on the distribution of the data and treatment number, the results obtained were analysed using 1-way ANOVA, Student's T-test, the Kruskal-Wallis test or the Mann-Whitney test on GraphPad Prism 5 software. Differences between groups were considered statistically significant when $\mathrm{p}<0.05$. The levels of probability are shown in the respective figures.

\section{Results}

\section{Short-term infection}

Quantification of parasites in the digestive tract

The infection rates of the $R$. prolixus digestive tract by $T$. rangeli were analysed on different days after feeding
(DAF). Analyses of the presence of parasites in the digestive tract showed that the percentage of infected insects at 2 DAF was $100 \%$ and decreased to $26.6 \%$ and $6.7 \%$ after 7 and 12 days, respectively. The anterior midgut presented a high number of parasites, starting with $9.7 \times 10^{5} / \mathrm{mL}$ at 2 DAF and decreased significantly along time to $9.3 \times 10^{4} /$ $\mathrm{mL}$ and 0 , respectively, at 7 and $12 \operatorname{DAF}(\mathrm{p}<0.001)$ (Figure 1). A similar pattern of parasite temporal distribution was observed in the posterior midgut and rectum with an infection level of $1.1 \times 10^{5} / \mathrm{mL}, 5.0 \times 10^{4} / \mathrm{mL}$ and $8.3 \times$ $10^{3} / \mathrm{mL}$ at 2,7 and $12 \mathrm{DAF}$, respectively with significant difference between 2 and $12 \operatorname{DAF}(\mathrm{p}<0.05)$ (Figure 1).

\section{Analysis of intestinal microbiota (CFU)}

Cultivable bacterial microbiota population in $5^{\text {th }}$ instar nymphs infected with $T$. rangeli Macias strain was evaluated using CFU counts of digestive tract preparations. At 12 DAF the bacterial population in infected insects $\left(5.7 \times 10^{7} \mathrm{CFU} / \mathrm{mL}\right)$ was significantly lower than the uninfected control $\left(2.0 \times 10^{8} \mathrm{CFU} / \mathrm{mL}\right)(\mathrm{p}<0.01)$ (Figure 2).

\section{Turbidimetric (TB) antibacterial assay}

The antibacterial activity in $5^{\text {th }}$ instar nymphs infected with $T$. rangeli was analysed in vitro by incubating anterior midgut content samples collected 7 DAF with different bacterial strains. Antibacterial activity of the infected insects against $S$. marcescens was significantly higher than in control insects $(\mathrm{p}<0.001)$ (Figure 3A). The activities measured against $S$. aureus and E. coli

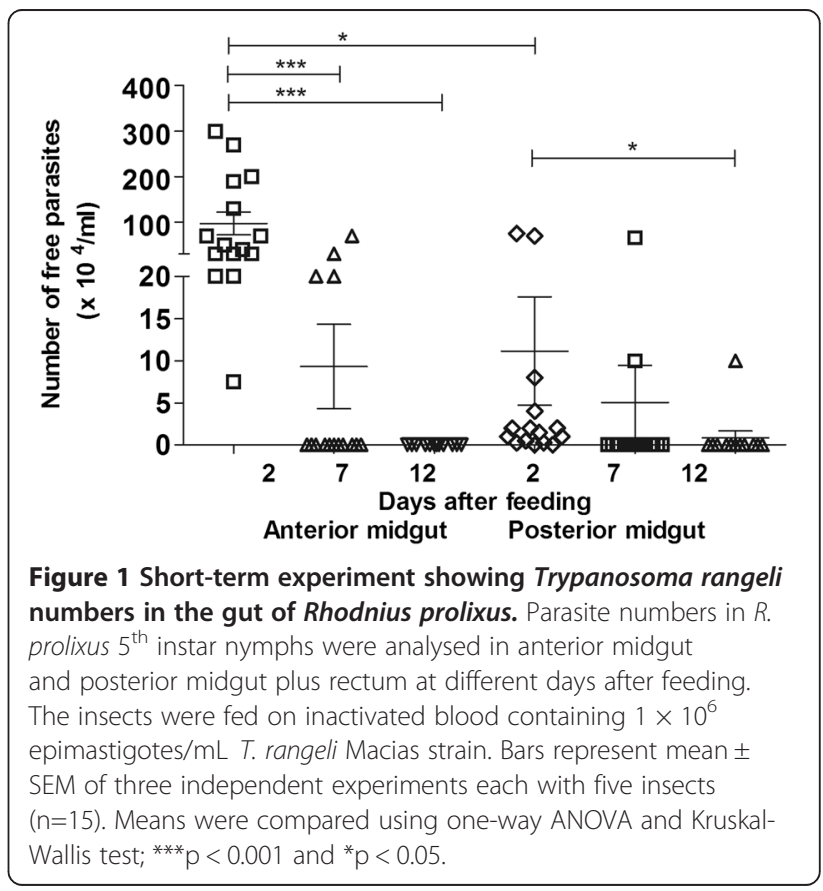




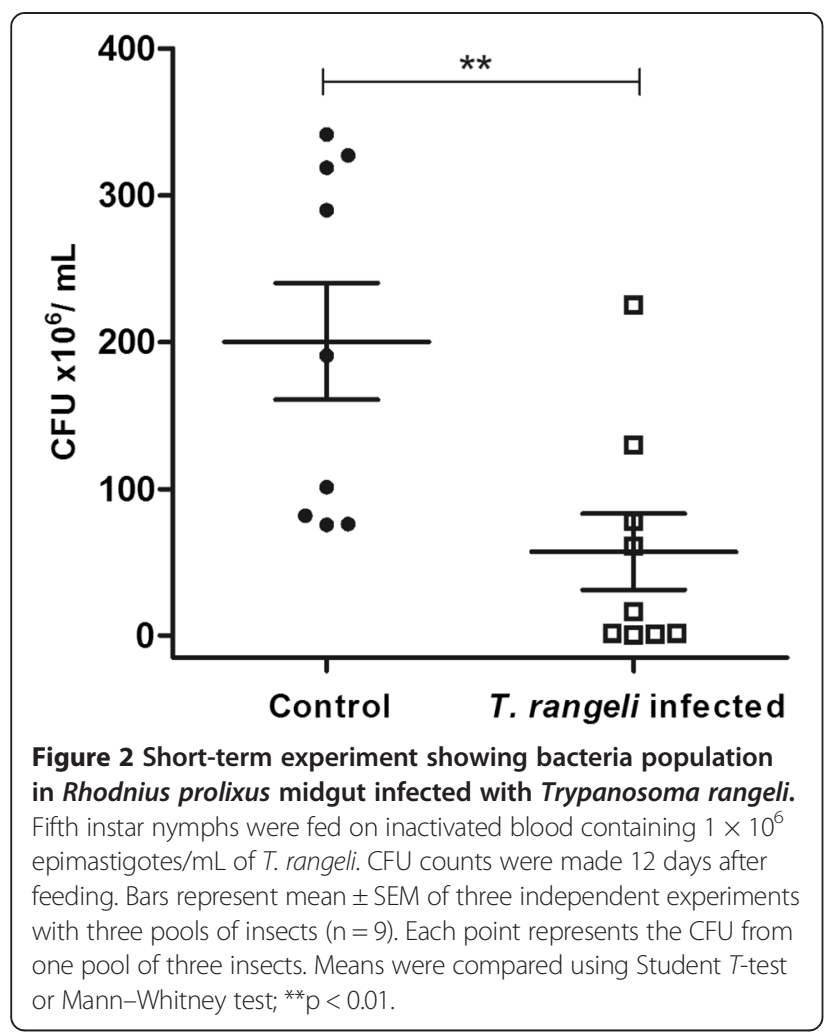

were similar in infected insects compared with the controls (Figure 3B, C).

\section{Transcript abundance of antimicrobial peptides (AMPs)}

The modification of antimicrobial activities in the anterior and posterior midguts of the $5^{\text {th }}$ instar nymphs infected with $T$. rangeli was analysed by the transcript abundance profiles of AMPs 1 and 7 DAF. The relative abundance of lysozyme A (LysA), lysozyme B (LysB), prolixicin (Prol), defensins A $(D e f A)$, B $(D e f B)$ and C $(D e f C)$ was also quantified (Figure 4).

In the anterior midgut at $1 \mathrm{DAF}$, the expression of $\operatorname{DefB}$ was significantly higher $(\mathrm{p}<0.05)$ and $L y s B$ was significantly lower $(\mathrm{p}<0.05)$ in comparison between infected and control insects, respectively (Figure 4A). In contrast, at 7 DAF, three AMPs (DefB, LysB and Prol) had significantly lower levels $(\mathrm{p}<0.001 ; \mathrm{p}<0.05$; $\mathrm{p}<0.001$, respectively) and only one $(D e f C)$ had a significantly higher level $(\mathrm{p}<0.001)$ of transcripts in infected insects when compared to control (Figure 4C). However, in the posterior midgut the differences in levels of the AMPs between the infected and control insects were less striking. Compared to control the infected insects presented higher levels $(\mathrm{p}<0.001)$ of DefC transcripts at 1 DAF and lower levels $(\mathrm{p}<0.001)$ of Prol at 7DAF (Figure $4 \mathrm{~B}$ and D).
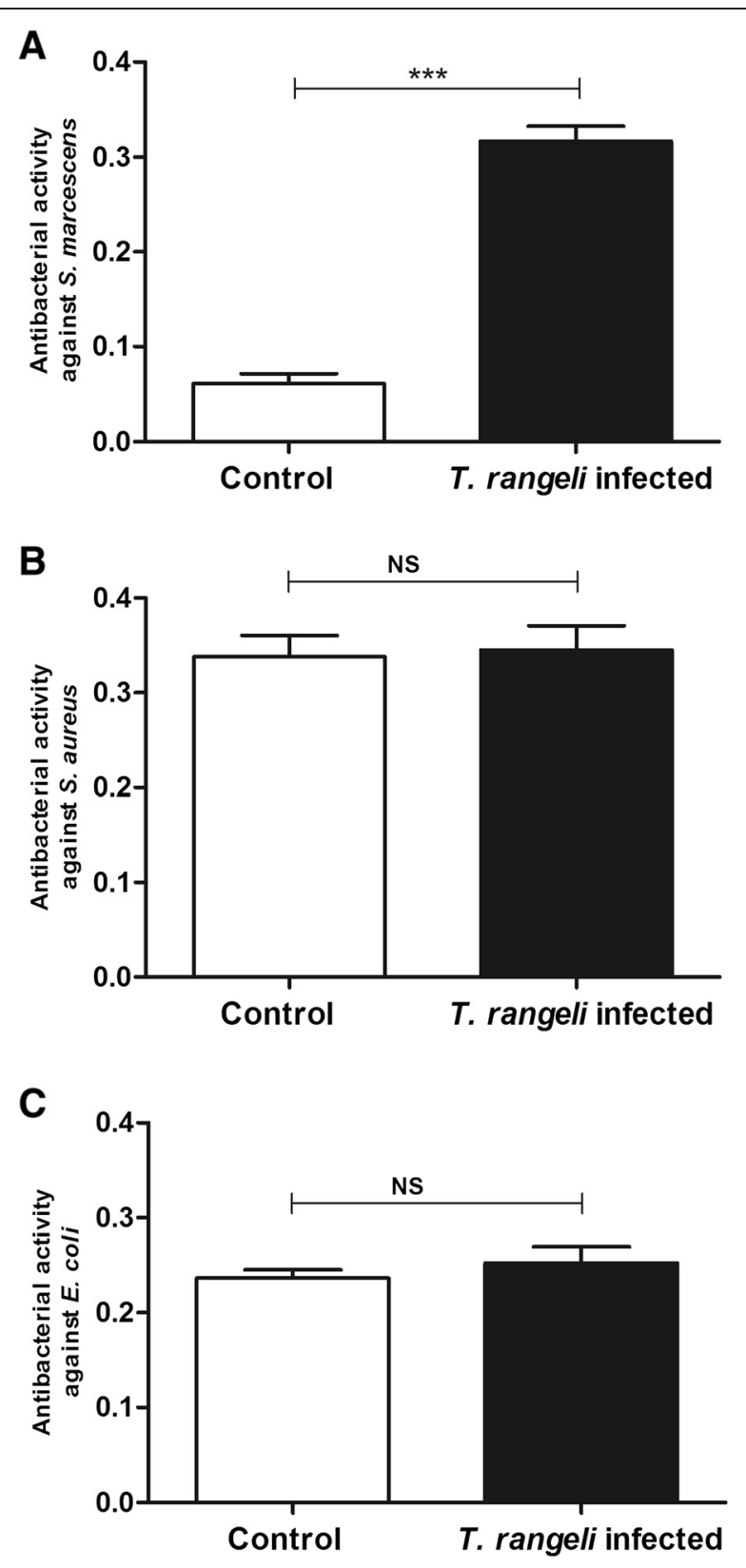

Figure 3 Short-term experiment showing antibacterial activity in the midgut of Rhodnius prolixus infected with Trypanosoma rangeli. The antibacterial activities of anterior midgut of $R$. prolixus $5^{\text {th }}$ instar nymphs 7 days after infection with $T$. rangeli were tested against (A) S. marcescens (B) S. aureus (C) E. coli. Treatments: white columns - control, uninfected group; black columns - infected group. Fifth instar nymphs were fed on inactivated blood with or without $1 \times 10^{6}$ epimastigotes $/ \mathrm{mL}$. Antibacterial activity value was measured using the turbidimetric assay (TB) $\left(\mathrm{OD}_{550} \mathrm{~nm}\right)$ after $19 \mathrm{~h}$ incubation of midgut samples with different bacteria and calculated by the difference between the optical densities of the midgut samples and bacterial control. Bars represent mean \pm SEM of three independent experiments. Each experiment consisted of three pools of three insects $(n=9)$. Means were compared using $t$-test; ${ }^{* * *} \mathrm{p}<0.001$ and $\mathrm{NS}=$ not significant. 


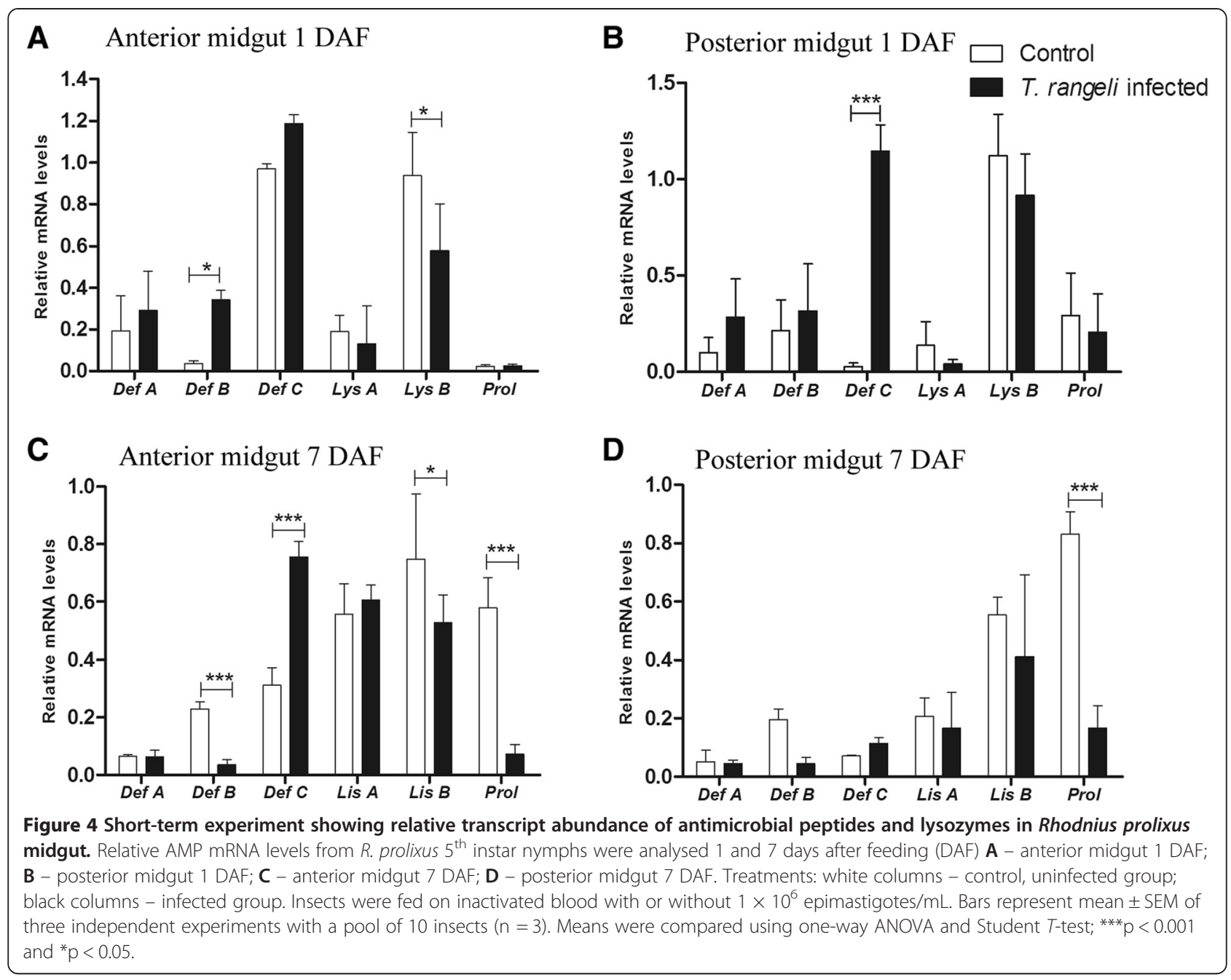

\section{Determination of phenoloxidase activity}

PO activities measured in the anterior midgut contents of the $5^{\text {th }}$ instar nymphs at 7 DAF did not show significant differences, when comparing $T$. rangeli infected and control groups. However, at 12 DAF, the PO activity was significantly lower in infected insects than in the control $(\mathrm{p}<0.01)$ (Figure 5$)$. The PO activity inhibition by $T$. rangeli infection was significantly higher at 12 DAF when compared with 7 DAF $(\mathrm{p}<0.001)$ (Figure 5).

\section{Long term infection}

\section{Quantification of parasites in the digestive tract}

The $T$. rangeli infection in the insects was also investigated in long-term experiments. Parasites were quantified in the digestive tract from the $4^{\text {th }}$ instar nymphs when infection occurred and after insects moulted to $5^{\text {th }}$ instar followed by a second feeding with parasite free blood. The percentages of infected insects in $4^{\text {th }}$ instar nymphs at 2 and 7 days after infection were $86.7 \%$ and $93.3 \%$, respectively. In this infected group, the number of parasites encountered in the anterior midgut was significantly higher than in the posterior midgut on both days analysed (Figure 6A). The parasite numbers reached $28.9 \times 10^{4} / \mathrm{mL}$ and $32.8 \times 10^{4} / \mathrm{mL}$ in the anterior midgut at 2 and 7 DAF, respectively, and $3.4 \times 10^{4} / \mathrm{mL}$ and $4.4 \times$ $10^{4} / \mathrm{mL}$ in the posterior midgut at 2 and $7 \mathrm{DAF}$, respectively (Figure 6A).

The percentages of $5^{\text {th }}$ instar nymphs which showed $T$. rangeli infection in the digestive tract were $46.7 \%$ and $73.3 \%$ at 2 and 7 DAF, respectively, after an uninfected blood meal. In these $5^{\text {th }}$ instar nymphs, the results were opposite to those observed in the $4^{\text {th }}$ instar nymphs, in which the anterior midgut presented significantly lower numbers of parasites than the posterior midgut on both days analysed (Figure 6B). The infection level in the anterior midgut was 0 and $0.17 \times 10^{4} / \mathrm{mL}$ at 2 and 7 DAF respectively and in the posterior midgut and rectum was $22.4 \times 10^{4} / \mathrm{mL}$ and $17.7 \times 10^{4} / \mathrm{mL}$ at 2 and 7 DAF, respectively (Figure 6B). These results showed that $T$. rangeli successfully colonized $R$. prolixus midgut, even after moulting and a second blood meal (Figure 6). 


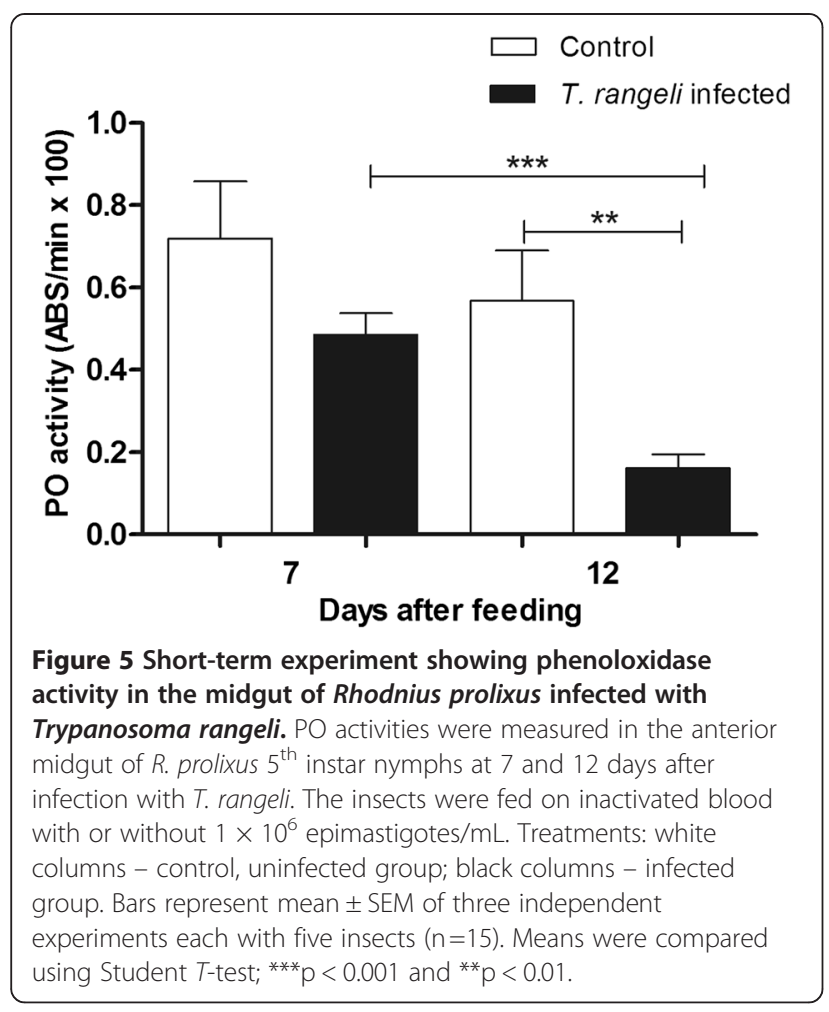

\section{Analysis of intestinal microbiota}

\section{Colony forming unit (CFU)}

The cultivable bacterial microbiota population of $R$. prolixus $5^{\text {th }}$ instar nymphs, infected as $4^{\text {th }}$ instars with $T$. rangeli was significantly lower than control insects at 12 DAF $(\mathrm{p}<0.01)$ (Figure 7).

\section{Amplification and 454 sequencing of targeted 16S rRNA gene variable region}

The bacterial microbiota in the anterior midgut was predominantly composed of Enterobacteriaceae and Enterococcaceae families, which include Serratia and

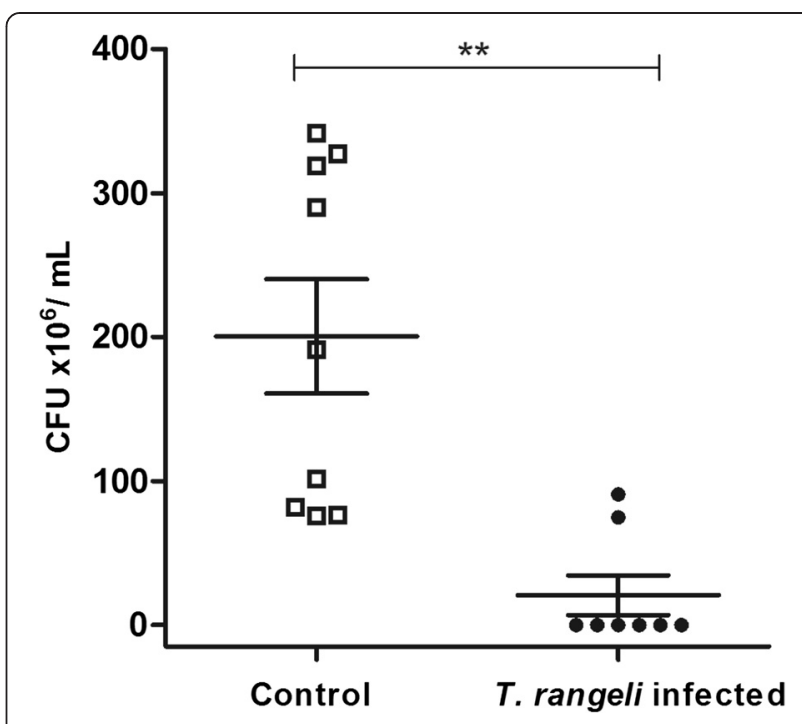

Figure 7 Long-term experiment showing bacteria population in Rhodnius prolixus midgut infected with Trypanosoma rangeli. CFU counts were made with $R$. prolixus $5^{\text {th }}$ instar nymphs 12 days after feeding (DAF) on blood without parasites. Previously, $4^{\text {th }}$ instar nymphs were fed on inactivated blood with or without $1 \times 10^{6}$ epimastigotes $/ \mathrm{mL}$. Bars represent mean \pm SEM of three independent experiments. Each point represents the CFU from three pools of three insects $(n=9)$. Means were compared using Student T-test or Mann-Whitney test; ${ }^{* *} p<0.01$ and ${ }^{*} p<0.05$

Enterococcus species, respectively, as well as Nocardiaceae (Figure 8). Seven days after feeding, there was a significant decrease of Enterococcaceae in the $R$. prolixus $5^{\text {th }}$ instar nymphs, infected at $4^{\text {th }}$ instar with $T$. rangeli while there was significant increase of Burkholderiaceae in the infected $5^{\text {th }}$ instar nymphs (Figure 8 ).

Turbidimetric antibacterial assay

The anterior midgut antibacterial activity of insects infected over the long-term was investigated. Comparing to the control group, infected insects presented significantly
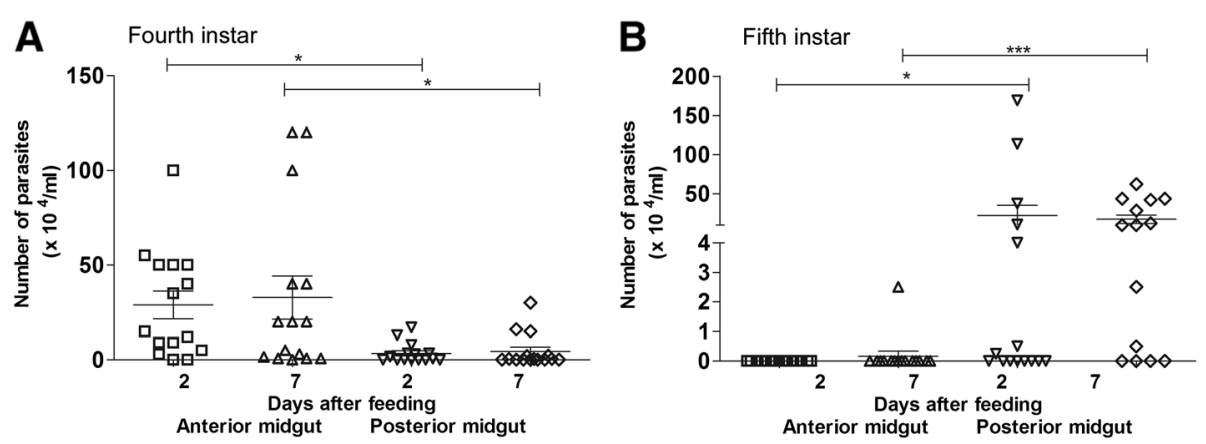

Figure 6 Long-term experiment showing Trypanosoma rangeli numbers in the gut of Rhodnius prolixus. Parasite numbers were analysed in $R$. prolixus (A) $4^{\text {th }}$ and (B) $5^{\text {th }}$ instar nymphs: anterior midgut and posterior midgut at 2 and 7 days after feeding. Fourth instar nymphs were fed on inactivated blood containing $1 \times 10^{6}$ epimastigotes $/ \mathrm{mL}$. After moulting, $5^{\text {th }}$ instar nymphs were fed on blood without parasites. Bars represent mean \pm SEM of three independent experiments each with five insects $(n=15)$. Means were compared using one-way ANOVA and Kruskal-Wallis test; ${ }^{* *} p<0.001$ and ${ }^{*} p<0.05$ 


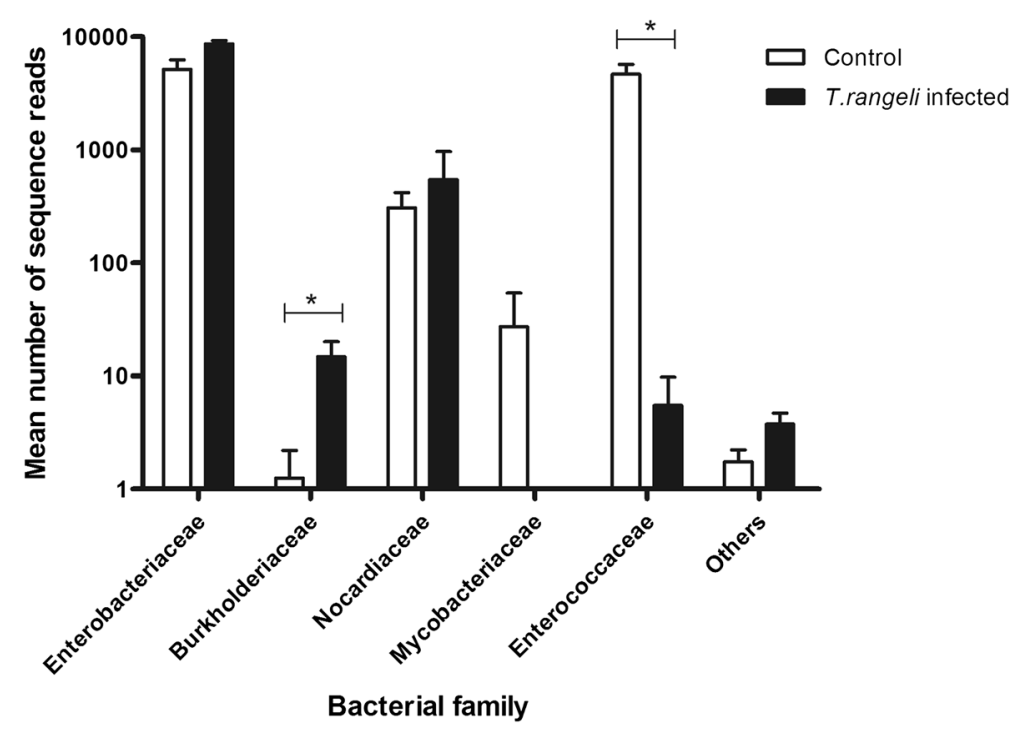

Figure 8 Bacterial composition identified by 16S ribosomal pyrosequencing in Rhodnius prolixus midgut infected with Trypanosoma rangeli. Long-term experiment showing bacterial composition at the family levels. Pyrosequencing 454 experiments of anterior midgut preparations from R. prolixus $5^{\text {th }}$ instar nymphs 7 days after feeding (DAF) on blood without parasites. Previously, $4^{\text {th }}$ instar nymphs were fed on inactivated blood with or without $1 \times 10^{6}$ epimastigotes $/ \mathrm{mL}$ of $T$. rangeli. Each bar graph presents the mean number of sequence reads assigned to a given bacterial family in four insect samples. Others: represent families with only one or two sequences (Pseudomonadaceae, Comamonadaceae, Rhodobacteraceae, Phyllobacteriaceae, Bradyrhizobiaceae, Staphylococcaceae, Bacillaceae, Nitrospiraceae, Flavobacteriaceae). Means were compared using t-test or Mann-Whitney test; ${ }^{*} p<0.05$.

higher antibacterial activity against $S$. marcescens $(\mathrm{p}<$ $0.001)$ and $S$. aureus $(\mathrm{p}<0.05)$ and lower activity against E. coli $(\mathrm{p}<0.001)$ (Figure 9).

\section{Transcript abundance of antimicrobial peptides (AMPs)}

The relative transcript abundance of AMPs and lysozymes encoding mRNA in the $5^{\text {th }}$ instar $R$. prolixus nymphs that were infected with $T$. rangeli as $4^{\text {th }}$ instar nymphs was investigated (Figure 10). The expression of LysB was significantly lower in both compartments of the midgut at 1 and 7 DAF in infected insects when compared to the uninfected control group. This difference in abundance of $L y s B$ was more significant at 1 DAF $(\mathrm{p}<0.001)$ both in the anterior and posterior midguts of the infected insects (Figure 10A and 10B). The abundance of Lys A transcripts was significantly lower only in the anterior midgut at 7 DAF of the infected insects $(p<0.05)$ in comparison to the control insects (Figure 10C). Compared to the control group, DefC transcripts in infected insects were less abundant in the anterior midgut at 1 DAF $(\mathrm{p}<0.001)$. In the posterior midgut at 7 DAF abundance of the $D e f B$ transcripts was lower $(\mathrm{p}<0.01)$ in infected insects than in the control insects (Figure 10D). Moreover, the abundance of Prol was significantly lower in the anterior midgut at 7 DAF $(\mathrm{p}<$ $0.001)$ and in the posterior midgut at 1 and 7 DAF $(\mathrm{p}<$ 0.01) of infected insects when compared to control (Figures 10 B, C and D). Only DefC mRNA levels in the posterior midgut were up-regulated $(57$-fold, $\mathrm{p}<0.001$ ) at 1 DAF in infected insects when compared to the control group (Figure 10B).

\section{Prophenoloxidase (PPO) activity}

The anterior midgut of $5^{\text {th }}$ instar nymphs, previously infected with $T$. rangeli at $4^{\text {th }}$ instar, were investigated. The PO activities of infected insects were significantly lower than the control insects at 7 and 12 DAF ( $p<0.001$ and $\mathrm{p}<0.01$, respectively) (Figure 11). Moreover, the PO activity in the control insects was lower at 12 DAF when compared to 7 DAF $(\mathrm{p}<0.01)$ (Figure 11$)$.

\section{Discussion}

Experiments in which $R$. prolixus were infected with $T$. rangeli $\mathrm{H} 14$ or Choachi strains have demonstrated that the modulation of the insect's immune responses and subsequent establishment of the infection in the digestive tract depends on the strain of the parasite [25,40-44]. It is also known that gut microbiota can be correlated to the success of the parasite infection in diverse invertebrate hosts [17,45-48]. Therefore, we infected $R$. prolixus with the $T$. rangeli Macias strain and investigated the modulation of the immune system and bacteria population of the insect's digestive tract. Our results demonstrated that the percentage of insects with intestinal parasites varied within days after infection and midgut compartments examined. In the short-term infection, $T$. rangeli predominantly colonized the anterior midgut and the number of parasites decreased over time. 

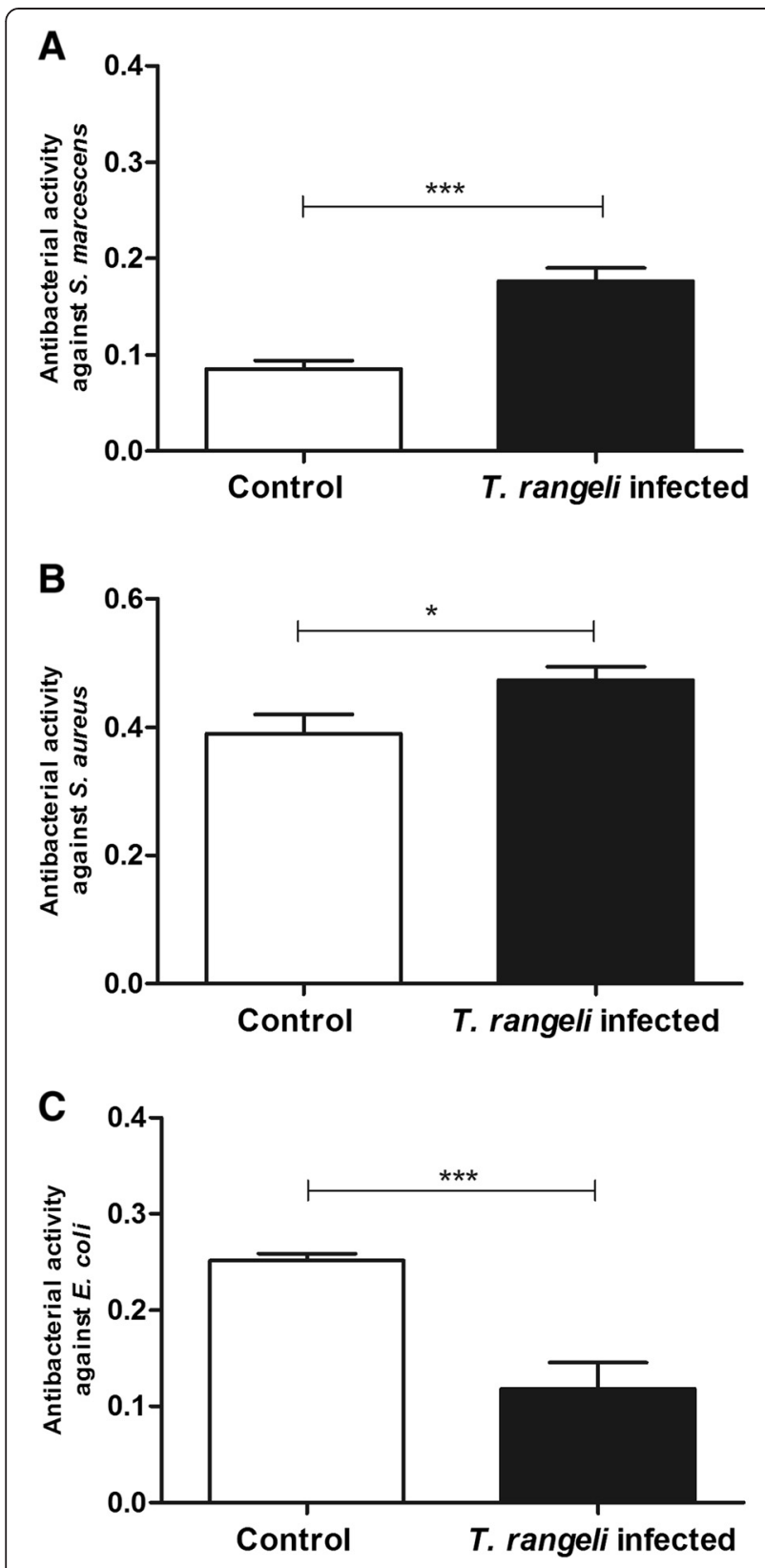

Figure 9 Long-term experiment showing antibacterial activity in the midgut of Rhodnius prolixus infected with Trypanosoma rangeli. Antibacterial activities of anterior midgutof $R$. prolixus $5^{\text {th }}$ instar nymphs 7 days after feeding (DAF) on blood without parasiteswere tested against (A) S. marcescens(B) S. aureus (C) E. coli. Treatments: white columns - control, uninfected group; black columns - infected group. Previously, $4^{\text {th }}$ instar nymphs were fed on inactivated blood with or without $1 \times 10^{6}$ epimastigotes $/ \mathrm{mL}$. Anterior midgut contents were collected from $5^{\text {th }}$ instar nymphs 7 (DAF). Antibacterial activity was measured using the turbidimetric assay (TB) $\left(\mathrm{OD}_{550} \mathrm{~nm}\right)$ after $19 \mathrm{~h}$ incubation of midgut samples with different bacteria and calculated by the difference between the optical densities of the midgut samples and bacterial control. Bars represent mean \pm SEM of three independent experiments. Each experiment consisted of three pools of three insects $(n=9)$. Means were compared using Student T-test; ${ }^{* *} p<0.001$ and ${ }^{*} p<0.05$.
In the long-term experiments, the parasites were found preferentially in the anterior midgut of the $4^{\text {th }}$ instar nymphs; however after moulting and receiving a parasite-free blood meal, $T$. rangeli was predominantly found in the posterior midgut of the $5^{\text {th }}$ instar nymphs. In terms of $T$. cruzi development in triatomines, the parasites migrate to the posterior midgut and rectum within few weeks after infection [49-52]. Depending on the nutritional conditions of the insect, the anterior midgut contains different microbiota compositions and cytotoxic components (nitrogen and oxygen reactive species, AMPs and haemolysins) that may create a hostile environment for the parasites [20,36,51,53-56].

It is known that the intestinal microbiota modulates the host immune responses and can interfere in parasite infection $[12,57,58]$. Moreover, the bacteria density can be regulated depending on the parasite genotype infecting the insect host as observed with $T$. cruzi infection in $R$. prolixus [17]. The present study showed lower cultivable bacterial CFU numbers in the digestive tract of $R$. prolixus infected with $T$. rangeli than in control insects (short and long-term). Additionally, bacterial microbiota analysis by pyrosequencing revealed a decrease of Enterococcaceae and Mycobacteriaceae while Burkholderiaceae increased in sequence numbers in infected insects. In other insect vectors, such as Glossina and Anopheles, bacteria from these families have also been observed and they have varied with parasite infection as well $[59,60]$. Rhodococcus rhodnii and S. marcenscens that have been frequently observed colonizing triatomines [12,61,62] and which belong to the families Nocardiaceae and Enterobacteriaceae, respectively, were not altered after $T$. rangeli Macias strain infection in $R$. prolixus. However, $R$. rhodnii population decreased in a study using the $T$. rangeli Choachi strain infecting $R$. prolixus [63]. Additionally, in vitro studies have already shown that $S$. marcescens possess cytotoxicity against some T. cruzi and $T$. rangeli strains $[12,13,55,64,65]$ besides its antibiotic activity [66]. These findings indicate that bacterial communities can be modulated differently depending on the $T$. rangeli strain.

We analysed the antibacterial activity in the midgut of the $T$. rangeli infected insects and showed that this activity was related to the decrease in the bacteria population of the insect's digestive tract. The high antibacterial activity observed against $S$. marcescens in vitro can be one reason for the low number of cultivable bacteria detected in the CFU analysis. In addition, the high antimicrobial activity against $S$. aureus might reflect the decrease of Enterococcus in the midgut of infected samples analysed by pyrosequencing.

The production of AMPs in the insect gut has been demonstrated to be vital to maintain insect homeostasis of the intestinal microbiota which provide essential 


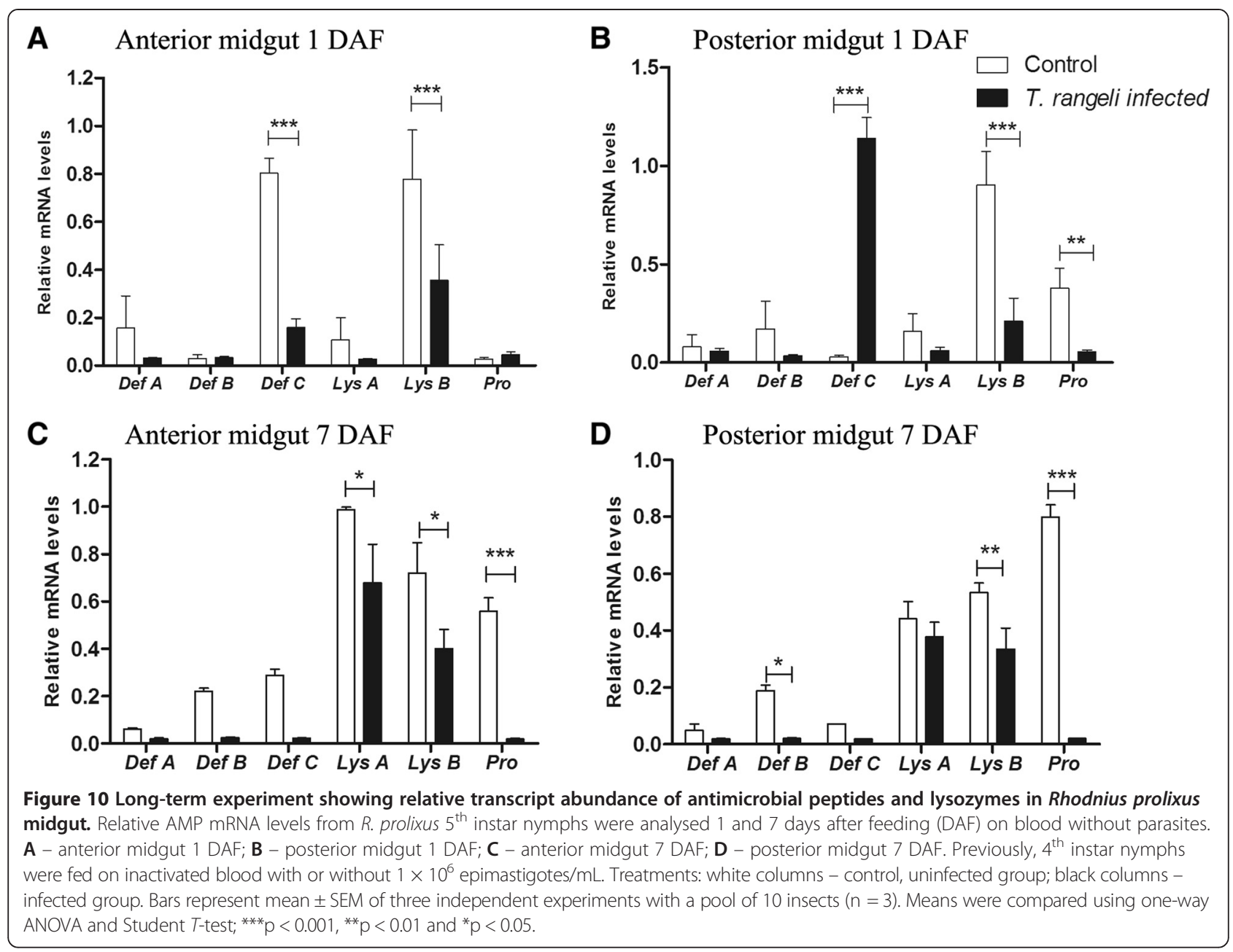

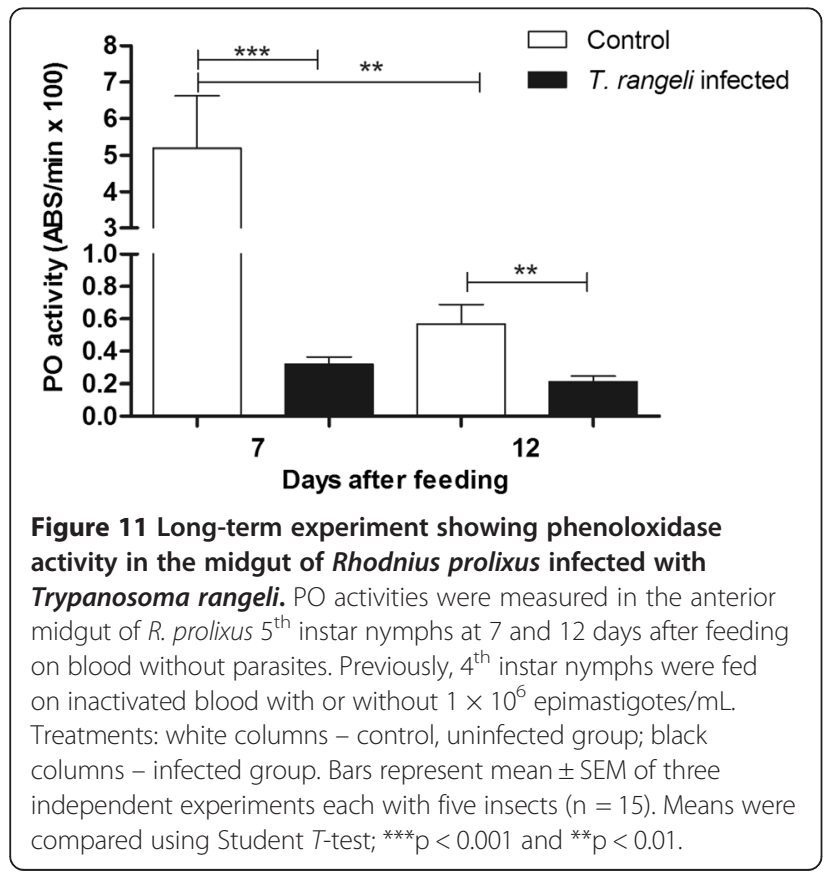

nutrients, promote digestion and control pathogenic microorganisms by modulating the immune responses [55,67-69]. In Drosophila the activation of signalling pathways of the immunity depends on the type of predominant microorganisms in the digestive tract [70-72].

An important immune response in the midgut lumen of insect vectors to control natural microbiota growth and pathogens is the production of AMPs [55,69]. AMPs are effectors molecules of the humoral immune system of insects that control microorganisms by disrupting cell membranes [73-75]. Analysis of the relative expression of mRNAs encoding lysozymes and AMPs in T. rangeli infected insects showed a different pattern in short and long-term infections. However, in general there was a suppression of most AMP genes. For example, $L y s B$ and Lys $A$ down-regulation was observed in the anterior and posterior midgut compartments. A previous work suggested that $L y s A$ is mainly expressed in the midgut with a digestive function while $L y s B$ is expressed in the fat body with an immune role [38]. Nevertheless, $S$. aureus oral infection in $R$. prolixus increased LysA mRNA levels in the midgut [36]. Combining these results with the suppression 
of LysA by T. rangeli infection observed herein, we suggest its involvement in the immune response.

Regarding prolixicin, a previous work showed that this peptide presented antimicrobial activities against Gramnegative and Gram-positive bacteria, but no toxicity against T. cruzi was detected [19]. In the present work, Prol was down-regulated in both midgut compartments, in both the short and long-term infections with T. rangeli. Although cytotoxicity of prolixicin against $T$. rangeli has not been described in the literature, the present results suggest that the modulation of Prol expression by T. rangeli could be one possible mechanism that, indirectly benefits the parasite's development in $R$. prolixus.

Another group of AMPs extensively studied in insects are the defensins. These peptides are known to act mainly on Gram-positive bacteria, but also show some activity against Gram-negative bacteria [76,77] and some protozoans such as Plasmodium and Trypanosoma [78-81]. Considering the short-term infection and the parasite population dynamics in the insect's midgut, a rapid increase of $D e f B$ levels and its subsequent down-regulation in the anterior midgut suggests a possible role of the respective peptides in the control of microorganism density in this compartment. The role of defensins in the control of trypanosomatid infections in the vector has been suggested previously $[80,82]$. On the other hand, the increase of DefC in both midgut compartments represents an immune modulation caused by $T$. rangeli that could represent a strategy to facilitate the establishment of $T$. rangeli in the gut of $R$. prolixus. Combined, these results suggest that an increase of antimicrobial activities and a decrease of CFU numbers detected in the anterior midgut in short term infection might be a result of the increased $D e f B$ and $D e f C$ levels observed. Long-term infection resulted in a massive up-regulation of $D e f C$ in the posterior midgut, which can explain the decrease of bacteria population encountered and the parasite's preference to develop in this midgut compartment. These results indicate that the parasite infection can modulate the insect's immune system, which consequently can influence the microbiota population in the insect's digestive tract.

Another important biological event in the $T$. rangeli cycle, in its invertebrate host, is its ability to modulate the PPO system in the triatomine haemolymph [83-85]. The presence of $T$. rangeli also reduced the level of PPO activation in vitro [86] and in vivo in $R$. prolixus haemolymph [22,84]. The present study is the first to demonstrate that the PO activity in the $R$. prolixus midgut was also inhibited after oral infection with $T$. rangeli. The PO activity in the midgut seems to be differently regulated accordingly to the trypanosomatid species. While T. rangeli has the ability to inhibit the insect PPO system, T. cruzi infection induces an increase in this immune response [17]. Other immune modulated factors such as reactive oxygen and nitrogen species may be involved in the development of the parasite in insect's midgut [17,87-89].

\section{Conclusion}

Parasite-microbiota competition for nutrients can change the bacteria composition in the $R$. prolixus midgut and subsequently modulate the insect's immune system. A direct modulation of the immune system by the parasite can also affect the microbiota population. The strategy of certain trypanosome species for successful infection of the invertebrate host is a complex interplay and depends on a tripartite interaction between parasite, insect immune system and bacteria $[46,59,60,90,91]$. These interactions are an important field for research, opening up new insights into the understanding of parasite-vector relationships [92]. A better understanding of the role of bacterial species composing the gut microbiota on host immunity against pathogens can lead to the development of new strategies to control vector-borne diseases.

\section{Competing interests}

The authors declare that they have no competing interests.

\section{Authors' contributions}

Conceived and designed the experiments: CSV, PJW, DPC, ESG and PA. Carried out the biochemical experiments: CSV, DPM, MBF and DPC. Performed the molecular experiments: CSV, PJW, MG, FFM. Analysis and interpretation of data: CSV, DPM, PJW, JMS, MBF, MG, FFM, and PA. Contributed reagents/materials: ESG and PA. Wrote the manuscript: CSV, PJW, DPC and PA. All authors read and approved the final manuscript.

\section{Acknowledgments}

This work was supported by grants from Conselho Nacional de Desenvolvimento Científico e Tecnológico (CNPq), Fundação Oswaldo Cruz (FIOCRUZ) (PAPES Project), Fundação de Amparo à Pesquisa do Estado do Rio de Janeiro (FAPERJ) and INCT-EM. We thank Dr. Norman Ratcliffe for English revision of this work.

\section{Author details}

'Laboratório de Bioquímica e Fisiologia de Insetos, Instituto Oswaldo Cruz, Fundação Oswaldo Cruz (IOC/FIOCRUZ), Rio de Janeiro, RJ, Brazil. ${ }^{2}$ Departamento de Entomologia Molecular, Instituto Nacional de Entomologia Molecular (INCT-EM), Rio de Janeiro, RJ, Brazil. ${ }^{3}$ Departamento de Ciências Ambientais, Instituto de Florestas, Universidade Federal Rural do Rio de Janeiro (UFRRJ), Seropédica, RJ, Brazil.

Received: 10 November 2014 Accepted: 13 February 2015

Published online: 01 March 2015

\section{References}

1. Watkins R. Histology of Rhodnius prolixus infected with Trypanosoma rangeli. J Invertebr Pathol. 1971;17:59-66.

2. Hoare CA. The trypanosomes of mammals: a zoological monograph. Oxford: Blackwell Scientific Publications; 1972.

3. Tobie EJ. Observations on development of Trypanosoma rangeli in hemocoel of Rhodnius prolixus. J Invertebr Pathol. 1970;15:118-25.

4. Guhl F, Vallejo GA. Trypanosoma (Herpetosoma) rangeli Tejera, 1920 - An updated review. Mem Inst Oswaldo Cruz. 2003;98:435-42.

5. Hecker H, Schwarzenbach M, Rudin W. Development and interactions of Trypanosoma rangeli in and with the reduviid bug Rhodnius prolixus. Parasitol Res. 1990;76:311-8.

6. Garcia ES, Mello CB, Azambuja P, Ribeiro JMC. Rhodnius prolixus - salivary antihemostatic components decrease with Trypanosoma rangeli infection. Exp Parasitol. 1994;78:287-93. 
7. Azambuja P, Garcia ES. Trypanosoma rangeli interactions within the vector Rhodnius prolixus: a mini review. Mem Inst Oswaldo Cruz. 2005;100:567-72.

8. Garcia ES, Castro DP, Figueiredo MB, Azambuja P. Parasite mediated interactions within the insect vector: Trypanosoma rangeli strategies. Parasit Vectors. 2012;5:105

9. Garcia ES, Ratcliffe NA, Whitten MM, Gonzalez MS, Azambuja P. Exploring the role of insect host factors in the dynamics of Trypanosoma cruzi-Rhodnius prolixus interactions. J Insect Physiol. 2007:53:11-21.

10. Garcia ES, Castro DP, Figueiredo MB, Genta FA, Azambuja P. Trypanosoma rangeli: a new perspective for studying the modulation of immune reactions of Rhodnius prolixus. Parasit Vectors. 2009;2:33.

11. Figueiredo MB, Genta FA, Garcia ES, Azambuja P. Lipid mediators and vector infection: Trypanosoma rangeli inhibits Rhodnius prolixus hemocyte phagocytosis by modulation of phospholipase A2 and PAF-acetylhydrolase activities. J Insect Physiol. 2008,54:1528-37.

12. Azambuja P, Feder D, Garcia ES. Isolation of Serratia marcescens in the midgut of Rhodnius prolixus: impact on the establishment of the parasite Trypanosoma cruzi in the vector. Exp Parasitol. 2004;107:89-96.

13. Azambuja P, Garcia ES, Ratcliffe NA. Gut microbiota and parasite transmission by insect vectors. Trends Parasitol. 2005;21:568-72.

14. Azambuja PG, Guimarães JA, Garcia ES. Haemolytic factor from the crop of Rhodnius prolixus: evidence and partial characterization. J Insect Physiol. 1983;29:5.

15. Pulido XC, Perez G, Vallejo GA. Preliminary characterization of a Rhodnius prolixus hemolymph trypanolytic protein, this being a determinant of Trypanosoma rangeli KP1(+) and KP1(-) subpopulations vectorial ability. Mem Inst Oswaldo Cruz. 2008;103:172-9.

16. Mello CB, Nigam Y, Garcia ES, Azambuja P, Newton RP, Ratcliffe NA. Studies on a haemolymph lectin isolated from Rhodnius prolixus and its interaction with Trypanosoma rangeli. Exp Parasitol. 1999:91:289-96.

17. Castro DP, Moraes C, Gonzalez M, Ratcliffe N, Azambuja P, Garcia E. Trypanosoma cruzi immune response modulation decreases microbiota in Rhodnius prolixus gut and is crucial for parasite survival and development. PLoS One. 2012;7:e36591.

18. Waniek PJ, Castro HC, Sathler PC, Miceli L, Jansen AM, Araujo CAC. Two novel defensin-encoding genes of the Chagas disease vector Triatoma brasiliensis (Reduviidae, Triatominae): gene expression and peptide-structure modeling. J Insect Physiol. 2009;55:840-8.

19. Ursic-Bedoya R, Buchhop J, Joy JB, Durvasula R, Lowenberger C. Prolixicin: a novel antimicrobial peptide isolated from Rhodnius prolixus with differential activity against bacteria and Trypanosoma cruzi. Insect Mol Biol. 2011:20:775-86

20. Whitten M, Sun F, Tew I, Schaub G, Soukou C, Nappi A, et al. Differential modulation of Rhodnius prolixus nitric oxide activities following challenge with Trypanosoma rangeli, T. cruzi and bacterial cell wall components. Insect Biochem Mol Biol. 2007;37:440-52.

21. Garcia ES, Machado EM, Azambuja P. Inhibition of hemocyte microaggregation reactions in Rhodnius prolixus larvae orally infected with Trypanosoma rangeli. Exp Parasitol. 2004;107:31-8.

22. Garcia ES, Machado EM, Azambuja P. Effects of eicosanoid biosynthesis inhibitors on the prophenoloxidase-activating system and microaggregation reactions in the hemolymph of Rhodnius prolixus infected with Trypanosoma rangeli. J Insect Physiol. 2004;50:157-65.

23. Sociedade Brasileira de Ciências de Animais em Laboratório. COBEA. http://www.cobea.org.br. (2014). Accessed 10 Oct 2014

24. Schottelius J. Neuraminidase fluorescence test for the differentiation of Trypanosoma cruzi and Trypanosoma rangeli. Trop Med Parasitol. 1987:38:323-7.

25. Grisard EC, Steindel M, Guarneri AA, Eger-Mangrich I, Campbell DA, Romanha AJ. Characterization of Trypanosoma rangeli strains isolated in Central and South America: an overview. Mem Inst Oswaldo Cruz. 1999:94:203-9.

26. Vallejo GA, Guhl F, Carranza JC, Lozano LE, Sanchez JL, Jaramillo JC, et al. kDNA markers define two major Trypanosoma rangeli lineages in LatinAmerica. Acta Trop. 2002;81:77-82.

27. Azambuja P, Garcia ES. Care and maintenance of triatomine colonies. In: Crampton JM, Beard CB, Louis C, editors. Molecular biology of insect disease vectors: a methods manual. London: Chapman and Hall; 1997. p. 56-64.

28. Bexfield A, Nigam Y, Thomas S, Ratcliffe NA. Detection and partial characterisation of two antibacterial factors from the excretions/secretions of the medicinal maggot Lucilia sericata and their activity against methicillin resistant Staphylococcus aureus (MRSA). Microbes Infect. 2004;6:1297-304.

29. Ferrand J, Patron K, Legrand-Frossi C, Frippiat JP, Merlin C, Alauzet C, et al. Comparison of seven methods for extraction of bacterial DNA from fecal and cecal samples of mice. J Microbiol Methods. 2014;105:180-5.

30. Andersson AF, Lindberg M, Jakobsson $H$, Backhed F, Nyren P, Engstrand L. Comparative analysis of human gut microbiota by barcoded pyrosequencing. PLoS One. 2008;3:e2836.

31. National Institute of Health Common Fund Human Microbiome Project (HMP) http://www.hmpdacc.org. (2014). Accessed 15 Sept 14

32. Nawrocki EP, Eddy SR. Query-dependent banding (QDB) for faster RNA similarity searches. PLoS Comput Biol. 2007;3:e56.

33. Edgar RC, Haas BJ, Clemente JC, Quince C, Knight R. UCHIME improves sensitivity and speed of chimera detection. Bioinformatics. 2011;27:2194-200

34. Wang Q, Garrity GM, Tiedje JM, Cole JR. Naive Bayesian classifier for rapid assignment of rRNA sequences into the new bacterial taxonomy. Appl Environ Microbiol. 2007;73:5261-7.

35. Cole JR, Wang Q, Cardenas E, Fish J, Chai B, Farris RJ, et al. The ribosomal database project: improved alignments and new tools for rRNA analysis. Nucleic Acids Res. 2009:37:D141-5.

36. Vieira CS, Waniek PJ, Mattos DP, Castro DP, Mello CB, Ratcliffe NA, et al. Humoral responses in Rhodnius prolixus: bacterial feeding induces differential patterns of antibacterial activity and enhances mRNA levels of antimicrobial peptides in the midgut. Parasit Vectors. 2014;7:232.

37. Lopez L, Morales G, Ursic R, Wolff M, Lowenberger C. Isolation and characterization of a novel insect defensin from Rhodnius prolixus, a vector of Chagas disease. Insect Biochem Mol Biol. 2003;33:439-47.

38. Ursic-Bedoya RJ, Nazzari H, Cooper D, Triana O, Wolff M, Lowenberger C Identification and characterization of two novel lysozymes from Rhodnius prolixus, a vector of Chagas disease. J Insect Physiol. 2008;54:593-603.

39. Genta FA, Souza RS, Garcia ES, Azambuja P. Phenol oxidases from Rhodnius prolixus: temporal and tissue expression pattern and regulation by ecdysone. J Insect Physiol. 2010;56:1253-9.

40. Machado PE, Eger-Mangrich I, Rosa G, Koerich LB, Grisard EC, Steindel M. Differential susceptibility of triatomines of the genus Rhodnius to Trypanosoma rangeli strains from different geographical origins. Int J Parasitol. 2001;31:632-4.

41. Urrea DA, Carranza JC, Cuba CA, Gurgel-Goncalves R, Guhl F, Schofield CJ, et al. Molecular characterisation of Trypanosoma rangeli strains isolated from Rhodnius ecuadoriensis in Peru, R. colombiensis in Colombia and R. pallescens in Panama, supports a co-evolutionary association between parasites and vectors. Infect Genet Evol. 2005;5:123-9.

42. Whitten MM, Mello CB, Gomes SA, Nigam Y, Azambuja P, Garcia ES, et al. Role of superoxide and reactive nitrogen intermediates in Rhodnius prolixus (Reduviidae)/Trypanosoma rangeli interactions. Exp Parasitol. 2001;98:44-57.

43. Vallejo GA, Guhl F, Carranza JC, Triana O, Perez G, Ortiz PA, et al. Trypanosoma rangeli parasite-vector-vertebrate interactions and their relationship to the systematics and epidemiology of American trypanosomiasis. Biomedica. 2007;27 Suppl 1:110-8.

44. Vallejo GA, Guhl F, Schaub GA. Triatominae-Trypanosoma cruzi/T. rangeli. Vector-parasite interactions. Acta Trop. 2009;110:137-47.

45. Tchioffo MT, Boissiere A, Churcher TS, Abate L, Gimonneau G, Nsango SE, et al. Modulation of malaria infection in Anopheles gambiae mosquitoes exposed to natural midgut bacteria. PLoS One. 2013;8:e81663.

46. Weiss BL, Wang J, Maltz MA, Wu Y, Aksoy S. Trypanosome infection establishment in the tsetse fly gut is influenced by microbiome regulated host immune barriers. PLoS Pathog. 2013;9:e1003318.

47. Clayton AM, Dong Y, Dimopoulos G. The Anopheles innate immune system in the defense against malaria infection. J Innate Immun. 2014;6:169-81.

48. Sant'Anna MR, Diaz-Albiter H, Aguiar-Martins K, Al Salem WS, Cavalcante RR, Dillon VM, et al. Colonisation resistance in the sand fly gut: Leishmania protects Lutzomyia longipalpis from bacterial infection. Parasit Vectors. 2014;7:329.

49. Kollien AH, Schaub GA. The development of Trypanosoma cruzi in triatominae. Parasitol Today. 2000;16:381-7.

50. Carvalho-Moreira CJ, Spata MC, Coura JR, Garcia ES, Azambuja P, Gonzalez MS, et al. In vivo and in vitro metacyclogenesis tests of two strains of Trypanosoma cruzi in the triatomine vectors Triatoma pseudomaculata and Rhodnius neglectus: short/long-term and comparative study. Exp Parasitol. 2003;103:102-11. 
51. Cortez MR, Provencano A, Silva CE, Mello CB, Zimmermann LT, Schaub GA, et al. Trypanosoma cruzi: effects of azadirachtin and ecdysone on the dynamic development in Rhodnius prolixus larvae. Exp Parasitol. 2012;131:363-71.

52. Araujo CAC, Waniek PJ, Jansen AM. TCl/TCll co-infection can enhance Trypanosoma cruzi growth in Rhodnius prolixus. Parasit Vectors. 2014;7:94

53. Terra WR. Evolution of digestive system of insects - review. Annu Rev Entomol. 1990;35:181-200.

54. Kollien AH, Gonçalves TC, De Azambuja P, Garcia ES, Schaub GA. The effect of azadirachtin on fresh isolates of Trypanosoma cruzi in different species of triatomines. Parasitol Res. 1998;84:286-90.

55. Garcia ES, Genta FA, de Azambuja P, Schaub GA. Interactions between intestinal compounds of triatomines and Trypanosoma cruzi. Trends Parasitol. 2010;26:499-505.

56. Waniek PJ, Pacheco Costa JE, Jansen AM, Costa J, Araujo CAC. Cathepsin L of Triatoma brasiliensis (Reduviidae, Triatominae): sequence characterization, expression pattern and zymography. J Insect Physiol. 2012;58:178-87.

57. Lee WJ. Bacterial-modulated signaling pathways in gut homeostasis. Sci Signal. 2008;1:pe24.

58. Ha EM, Lee KA, Seo YY, Kim SH, Lim JH, Oh BH, et al. Coordination of multiple dual oxidase regulatory pathways in responses to commensal and infectious microbes in drosophila gut. Nat Immunol. 2009;10:949-57.

59. Geiger A, Fardeau ML, Njiokou F, Ollivier B. Glossina spp. gut bacterial flora and their putative role in fly-hosted trypanosome development. Front Cell Infect Microbiol. 2013;3:34.

60. Gendrin M, Christophides G. The Anopheles mosquito microbiota and their impact on pathogen transmission. In: Manguin S, editor. Anopheles mosquitoes - New insights into malaria vectors. Croatia: InTech; 2013. doi: $10.5772 / 55107$

61. Wigglesworth VB. ymbiotic bacteria in a blood-sucking insect, Rhodnius prolixus Stal (Hemiptera, Triatomidae). Parasitology. 1936;28:284-9.

62. da Mota FF, Marinho LP, Moreira CJ, Lima MM, Mello CB, Garcia ES, et al. Cultivation-independent methods reveal differences among bacterial gut microbiota in triatomine vectors of Chagas disease. PLoS Negl Trop Dis. 2012;6:e1631.

63. Eichler S, Schaub GA. Development of symbionts in triatomine bugs and the effects of infections with trypanosomatids. Exp Parasitol. 2002;100:17-27.

64. Castro DP, Moraes CS, Garcia ES, Azambuja P. Inhibitory effects of d-mannose on trypanosomatid lysis induced by Serratia marcescens. Exp Parasitol. 2007;115:200-4.

65. Castro DP, Seabra SH, Garcia ES, de Souza W, Azambuja P. Trypanosoma cruzi: ultrastructural studies of adhesion, lysis and biofilm formation by Serratia marcescens. Exp Parasitol. 2007;117:201-7.

66. Thomson NR, Crow MA, McGowan SJ, Cox A, Salmond GP. Biosynthesis of carbapenem antibiotic and prodigiosin pigment in Serratia is under quorum sensing control. Mol Microbiol. 2000;36:539-56.

67. Dillon RJ, Dillon VM. The gut bacteria of insects: nonpathogenic interactions. Annu Rev Entomol. 2004;49:71-92.

68. Leulier F, Royet J. Maintaining immune homeostasis in fly gut. Nat Immunol. 2009;10:936-8.

69. Schaub GA. Interactions of Trypanosomatids and Triatomines. Adv Insect Phys. 2009;37:177-242.

70. Nehme NT, Liegeois S, Kele B, Giammarinaro P, Pradel E, Hoffmann JA, et al. A model of bacterial intestinal infections in Drosophila melanogaster. PLoS Pathog. 2007:3:e173.

71. Ryu JH, Kim SH, Lee HY, Bai JY, Nam YD, Bae JW, et al. Innate immune homeostasis by the homeobox gene caudal and commensal-gut mutualism in Drosophila. Science. 2008;319:777-82.

72. Marmaras VJ, Lampropoulou M. Regulators and signalling in insect haemocyte immunity. Cell Signal. 2009;21:186-95.

73. Zasloff M. Antimicrobial peptides of multicellular organisms. Nature. 2002;415:389-95.

74. Bulet P, Stocklin R. Insect antimicrobial peptides: structures, properties and gene regulation. Protein PepT Lett. 2005;12:3-11.

75. Ferrandon D, Imler JL, Hetru C, Hoffmann JA. The Drosophila systemic immune response: sensing and signalling during bacterial and fungal infections. Nat Rev Immunol. 2007;7:862-74.

76. Bulet $P$, Cociancich S, Reuland M, Sauber F, Bischoff R, Hegy G, et al. A novel insect defensin mediates the inducible antibacterial activity in larvae of the dragonfly Aeschna cyanea (Paleoptera, Odonata). Eur J Biochem. 1992;209:977-84.
77. Lamberty M, Ades S, Uttenweiler-Joseph S, Brookhart G, Bushey D, Hoffmann JA, et al. Insect immunity. Isolation from the lepidopteran Heliothis virescens of a novel insect defensin with potent antifungal activity. J Biol Chem. 1999;274:9320-6.

78. Shahabuddin M, Fields I, Bulet P, Hoffmann JA, Miller LH. Plasmodium gallinaceum: differential killing of some mosquito stages of the parasite by insect defensin. Exp Parasitol. 1998;89:103-12.

79. Vizioli J, Richman AM, Uttenweiler-Joseph S, Blass C, Bulet P. The defensin peptide of the malaria vector mosquito Anopheles gambiae: antimicrobial activities and expression in adult mosquitoes. Insect Biochem Mol Biol. 2001;31:241-8

80. McGwire BS, Olson CL, Tack BF, Engman DM. Killing of African trypanosomes by antimicrobial peptides. J Infect Dis. 2003;188:146-52.

81. Kleschenko YE, Karpenko LP, Villalta F. Effects of human defensin- $a_{1}$ on Trypanosoma cruzi trypomastigotes in vitro. Bull Exp Biol Med. 2010;149:731-3.

82. Waniek PJ, Jansen AM, Araujo CAC. Trypanosoma cruzi infection modulates the expression of Triatoma brasiliensis def1 in the midgut. Vector Borne Zoonotic Dis. 2011;11:845-7.

83. Gomes SA, Feder D, Thomas NE, Garcia ES, Azambuja P. Rhodnius prolixus infected with Trypanosoma rangeli: In vivo and in vitro experiments. J Invertebr Pathol. 1999;73:289-93.

84. Gomes SA, Feder D, Garcia ES, Azambuja P. Suppression of the prophenoloxidase system in Rhodnius prolixus orally infected with Trypanosoma rangeli. J Insect Physiol. 2003;49:829-37.

85. Machado EM, Azambuja P, Garcia ES. WEB 2086, a platelet-activating factor antagonist, inhibits prophenoloxidase-activating system and hemocyte microaggregation reactions induced by Trypanosoma rangeli infection in Rhodnius prolixus hemolymph. J Insect Physiol. 2006;52:685-92.

86. Gregorio EA, Ratcliffe NA. The prophenoloxidase system and in vitro interaction of Trypanosoma rangeli with Rhodnius prolixus and Triatoma infestans haemolymph. Parasite Immunol. 1991;13:551-64.

87. Ascenzi P, Gradoni L. Nitric oxide limits parasite development in vectors and in invertebrate intermediate hosts. IUBMB Life. 2002;53:121-3.

88. Rivero A. Nitric oxide: an antiparasitic molecule of invertebrates. Trends Parasitol. 2006;22:219-25.

89. Cosentino-Gomes D, Rocco-Machado N, Meyer-Fernandes JR. Rhodnius prolixus: Modulation of antioxidant defenses by Trypanosoma rangeli. Exp Parasitol. 2014;145:118-24.

90. Cirimotich CM, Dong Y, Clayton AM, Sandiford SL, Souza-Neto JA, Mulenga $M$, et al. Natural microbe-mediated refractoriness to Plasmodium infection in Anopheles gambiae. Science. 2011;332:855-8.

91. Ramirez JL, Souza-Neto J, Torres Cosme R, Rovira J, Ortiz A, Pascale JM, et al. Reciprocal tripartite interactions between the Aedes aegypti midgut microbiota, innate immune system and dengue virus influences vector competence. PLoS Negl Trop Dis. 2012;6:e1561.

92. Weiss B, Aksoy S. Microbiome influences on insect host vector competence. Trends Parasitol. 2011;27:514-22.

\section{Submit your next manuscript to BioMed Central and take full advantage of:}

- Convenient online submission

- Thorough peer review

- No space constraints or color figure charges

- Immediate publication on acceptance

- Inclusion in PubMed, CAS, Scopus and Google Scholar

- Research which is freely available for redistribution 